\title{
Development and characterization of 49 novel microsatellite markers in the African catfish, Clarias gariepinus (Burchell, 1822)
}

\author{
Dóra Kánainé Sipos ${ }^{1} \cdot$ Katalin Bakos $^{1} \cdot$ Ágnes Ősz ${ }^{1} \cdot$ Árpád Hegyi $^{1} \cdot$ Tamás Müller $^{1} \cdot$ Béla Urbányi $^{1}$ · Balázs Kovács ${ }^{1}$ (I)
}

Received: 16 January 2019 / Accepted: 4 September 2019 / Published online: 18 September 2019

(c) The Author(s) 2019

\begin{abstract}
The African catfish or sharp tooth catfish (Clarias gariepinus) is one of the important species (due to its high environmental tolerance and easily controllable breeding habits) that can significantly contribute to reducing hunger in many countries. It is farmed in numerous African, Asian, and European countries. Moreover, during the last decades its production has grown significantly worldwide. Currently, following the carp, this species is produced in the second largest volume in Hungary. Despite its economic importance, the stocks have been maintained without genetic control or guided breeding. Molecular genetic data on bred populations or strains are very limited. In order to investigate the genetic structure of the stocks, 49 new microsatellite markers were characterized and tested on 32 individuals from a Hungarian farmed stock. All these markers were polymorph. The number of alleles per locus ranged from 2 to 11 . The observed and expected overall heterozygosities were between 0.519 and 0.544 respectively and the overall inbreeding coefficient (Fis: 0.063 ) does not reveal the presence of inbreeding. However, $63 \%$ of the markers showed significant deviations from HWE. The results suggest that the maintenance of genetic variation within the stock require high attention in closed bred populations. These new markers provide a useful tool for population and conservation genetics of natural and bred African catfish populations.
\end{abstract}

Keywords African catfish $\cdot$ Clarias gariepinus $\cdot$ Microsatellite $\cdot$ Genetic diversity $\cdot$ Population genetics $\cdot$ Anthropogenic effect

\section{Introduction}

The African catfish, Clarias gariepinus (Burchell, 1822), belongs to the Siluriformes order and the Clariidae family. It is native in Africa and the Middle East, but it was introduced to Europe, Asia, and South-America for aquaculture purposes [1]. This species represents an important resource in many developing countries with growing capture and aquaculture production. The latter increased tenfold, to over 200,000 metric tons in the last decade [1]. In the same time, the uncontrolled stocking and capture fishing have impacts on natural populations (e.g. fluctuating population size, decreasing genetic diversity, adaptability to changing environment and resistance to disease) [2,3].

Balázs Kovács

Kovacs.Balazs@mkk.szie.hu

1 Department of Aquaculture, Institute of Aquaculture and Environmental Safety, Faculty of Agricultural and Environmental Sciences, Szent István University, Páter K. u. 1, 2100 Gödöllő, Hungary
For the analyses of these issues, species-specific molecular genetic markers were developed for many fish species, including microsatellites due to their efficiency in individual identification, parentage analyses and differentiation of populations, lines or stocks. These markers are also widely used to estimate the population genetic values (such as variability, heterozygosity, inbreeding or genetic structure) [3, 4]. Due to the economic importance of the African catfish, more and more genetic studies analyze the genetic variability, yield deterioration and the conservation genetic background of farmed [5, 19] and natural [2] productions. However, the availability of the species-specific microsatellite markers suitable for detailed analysis of genetic resources are limited in number. Until now, only seven microsatellites have been described from the African catfish genome [6] and 12 microsatellites from other Clariidae species were used to investigate $C$. gariepinus [7]. However, cross-amplifying loci can lead to obvious complications (i.e.: monomorphic or low allele number of the loci; non-orthologous loci; size homoplasy), in population genetics and evolutionary studies [8]. In this study, new microsatellite loci were characterized 
for $C$. gariepinus by using repeat-enriched genomic library sequencing approach. These new markers are characterized on a bred population to provide new useful tools for population, conservational, evolutionary, and structural genetic studies on this species.

\section{Materials and methods}

The sampled African catfish individuals were originated from the stock of NAIK-HAKI Szarvas, Hungary (GPS: $46^{\circ} 52^{\prime} 0.01^{\prime \prime} \mathrm{N} 20^{\circ} 33^{\prime} 0.00^{\prime \prime} \mathrm{E}$ ). The stock was established in the mid-80 $\mathrm{s}$ and has been maintained in an intensive RAS system with closed breeding, however, some breeders were added to the broodstock unsystematically. For the genetic analyses and library preparation fin clips were collected from the tailfins $\left(0.5 \mathrm{~cm}^{2}\right.$ tissue $)$ of 32 individuals and the genomic DNA was isolated using E.Z.N.A. DNA Tissue Kit (Omega BioTek). DNAs were diluted to $50 \mathrm{ng} / \mu \mathrm{l}$ concentration for the microsatellite analyses and stored in Elution Buffer at $-20{ }^{\circ} \mathrm{C}$. Repeat enriched genomic DNA libraries were produced from pooled samples of three male specimens following the protocol of Glenn and Schable [9]. Rsa I, Hae III, Alu I, (Fermentas) and HpyCH4 V, (NewEngland BioLabs) endonucleases were used for DNA fragmentations. The Box I linker (F: 5'-Phos-ATG TCT GAA GGT ACC ACT GCT GTC CGA AA-3'; R: 5'-CGG ACA GCA GTG GTA CCT TCA GAC AT-3') was ligated to the ends of 300-1000 bp long isolated fragments. Biotinylated (CA) ${ }_{10}$ probe, linker specific oligo, and pGEM-T Easy Vector System I (Promega) were used for library preparations. The sequences of the inserts were determined by BigDye terminator sequencing (3130 Genetic Analyser, Applied Biosystems). The sequences were deposited in the NCBI GeneBank (see Table 1). Primer3Plus [10] software was used for primer design on the flanking regions of repeats (Table 1). Tailed and tail specific fluorescent primers were used to reduce the costs of detection, as it was described by Shimizu et al. [11]. A 17 base pair long tail (5'ATTACC GCGGCTGCTGG- microsatellite specific sequence- $3^{\prime}$ ) were added to the forward primers' $5^{\prime}$ ends to provide an attachment site for fluorescent dye labelled (FAM or VIC or NED or PET) tail-specific oligos. An additional labelled oligo was added to the reaction mixtures for fluorescent labelling of amplicons. Based on practical experiences the concentration of the labelled oligo was lower than the forward and reverse primers' to avoid the amplification of non specific fragments. The microsatellite PCRs were performed in 25 $\mu \mathrm{L}$ volumes including $1 \times T a q$ DNA polymerase buffer containing $\left(\mathrm{NH}_{4}\right)_{2} \mathrm{SO}_{4}$ or, buffer with $\mathrm{KCl}$ depending on which produced more abundant PCR products. The $\mathrm{KCl}$ containing buffer was used in case of the following markers $\mathrm{Cg} 02$, Cg03, Cg10, Cg40, Cg122 and Cg132 markers-Fermentas,
$264 \mathrm{nM}$ forward and reverse and $132 \mathrm{nM}$ tail-specificlabelled primers, $1.5-3.0 \mathrm{mM} \mathrm{MgCl}$ (Fermentas), $0.2 \mathrm{mM}$ dNTP (Fermentas), $0.04 \mathrm{U} / \mu \mathrm{L}$ Taq DNA polymerase (Fermentas) and $150 \mathrm{ng}$ template DNA. The thermocycling profile consisted of: preliminary denaturation at $95{ }^{\circ} \mathrm{C}$ for $2 \mathrm{~min}$, followed by two cycles of pre-amplification $\left(95{ }^{\circ} \mathrm{C} / 15 \mathrm{~s}\right.$; ann.temp./1 $\left.\mathrm{min} ; 72^{\circ} \mathrm{C} / 2 \mathrm{~min}\right)$ and $35(\mathrm{Cg} 002$, $\mathrm{Cg} 003, \mathrm{Cg} 010, \mathrm{Cg} 040, \mathrm{Cg} 122$ and $\mathrm{Cg} 132, \mathrm{Cg} 367, \mathrm{Cg} 652$, $\mathrm{Cg} 665)$ or 45 cycles of amplification $\left(95{ }^{\circ} \mathrm{C} / 15 \mathrm{~s}\right.$; ann. temp. $/ 20 \mathrm{~s} ; 72{ }^{\circ} \mathrm{C} / 40 \mathrm{~s}$ ) in case of the remaining ones. The reactions were closed by a final extension $\left(72^{\circ} \mathrm{C}\right.$ for $5 \mathrm{~min})$. The genotypes were determined by 3130 Genetic Analyser (Applied Biosystems) using GeneScan LIZ 500 size standard (Applied Biosystems). The alleles were identified and scored using GeneMAPPer 4.0 software (Applied Biosystems). Microsatellite Toolkit ver. 3.1.1 [12] was used to estimate the number of alleles per loci, mean number of alleles, polymorphic information content (PIC). The expected and observed heterozygosities and significance of deviation from Hardy-Weinberg equilibrium (HWE) were estimated by GeNAlEx ver. 6.5 [13]. The linkage disequilibrium was analyzed by Genetix 4.05 [14]. The minimum set of markers which provides a high resolution of parentage allocation and the probability of exclusion in paternity were tested by PARFEX v1.0 [15]. ML-Relate was used to maximum likelihood estimating of relatedness between individuals [16]. MICRO-CHECKER VER. 2.2.3 [17] was used to detect possible genotyping errors, allele dropout, and non-amplified alleles (null alleles), while the inbreeding coefficient $\left(\mathrm{F}_{\text {is }}\right)$ were calculated by FSTAT 2.9.3. [18].

\section{Results}

In total, 127 selected clones were sequenced from four CArepeat enriched genomic libraries. One hundred and eighteen clones contained microsatellite motifs. Based on the length (the PCR product would be 100-500 bp) and nucleotide composition (the PCR product would be specific and unique) of the flanking sequences 55 microsatellite sequences were selected and primers were synthesized for later PCR analyses. Forty-nine out of 55 markers were used to genotype the 32 individuals and amplified polymorphic alleles successfully. None of the 49 markers was monomorphic. The number of alleles per locus ranged from 2 to 11 , with a mean of 4.818 (SE: 1.973) alleles. The highest number (11) of amplified alleles was found in case of the $\mathrm{Cg} 175$ marker while $\mathrm{Cg} 003$ and $\mathrm{Cg} 010$ were also found to be highly polymorphic. The average polymorphic information content (PIC) value was 0.499 (from 0.142 to 0.763 ), 27 loci were highly polymorphic (PIC $>0.5$ ), 18 were moderately polymorphic $(0.2<$ PIC $<0.5)$, and four showed low polymorphism $(\mathrm{PIC}<0.2)$ in our bred population (Table 1 ). 


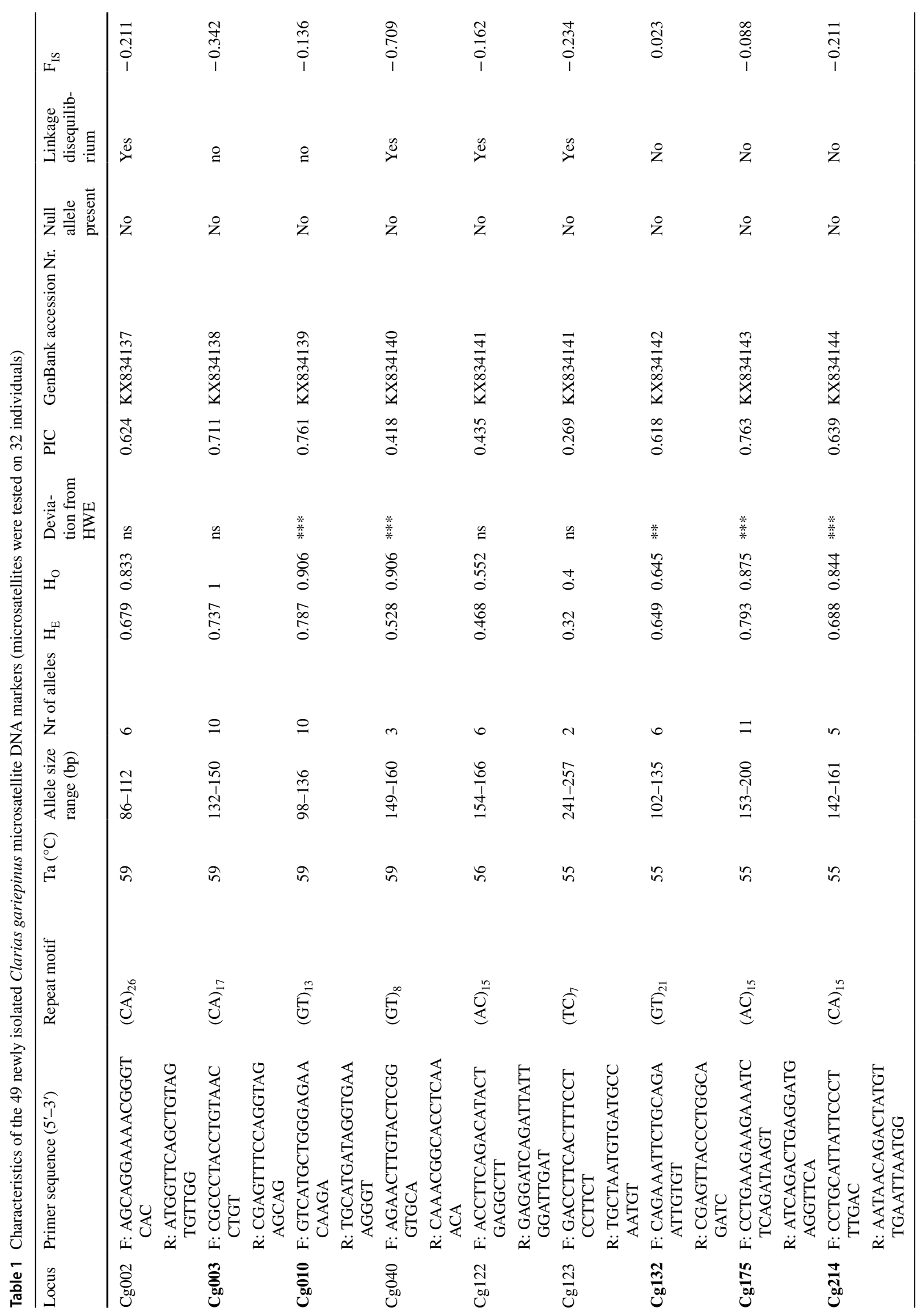




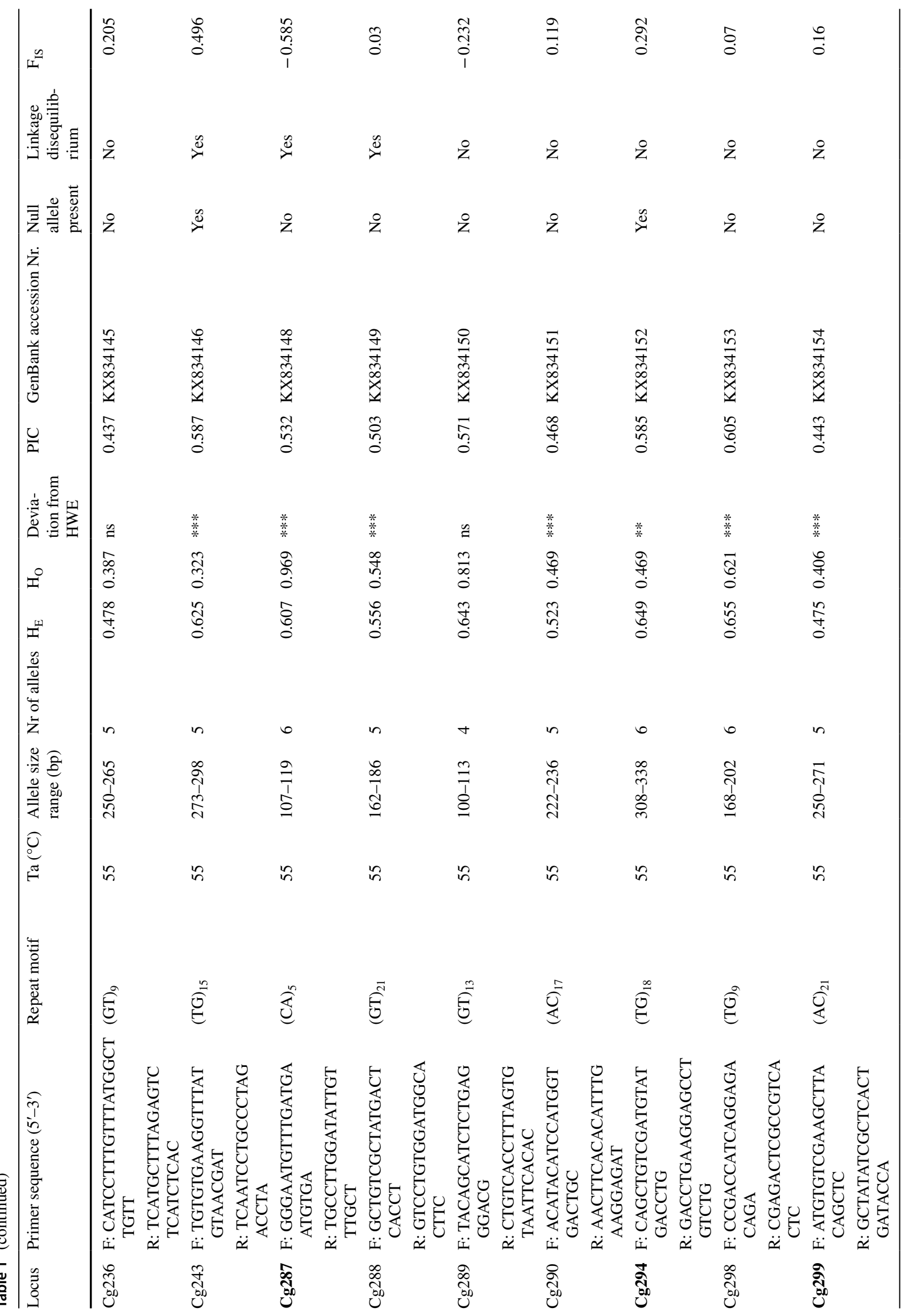




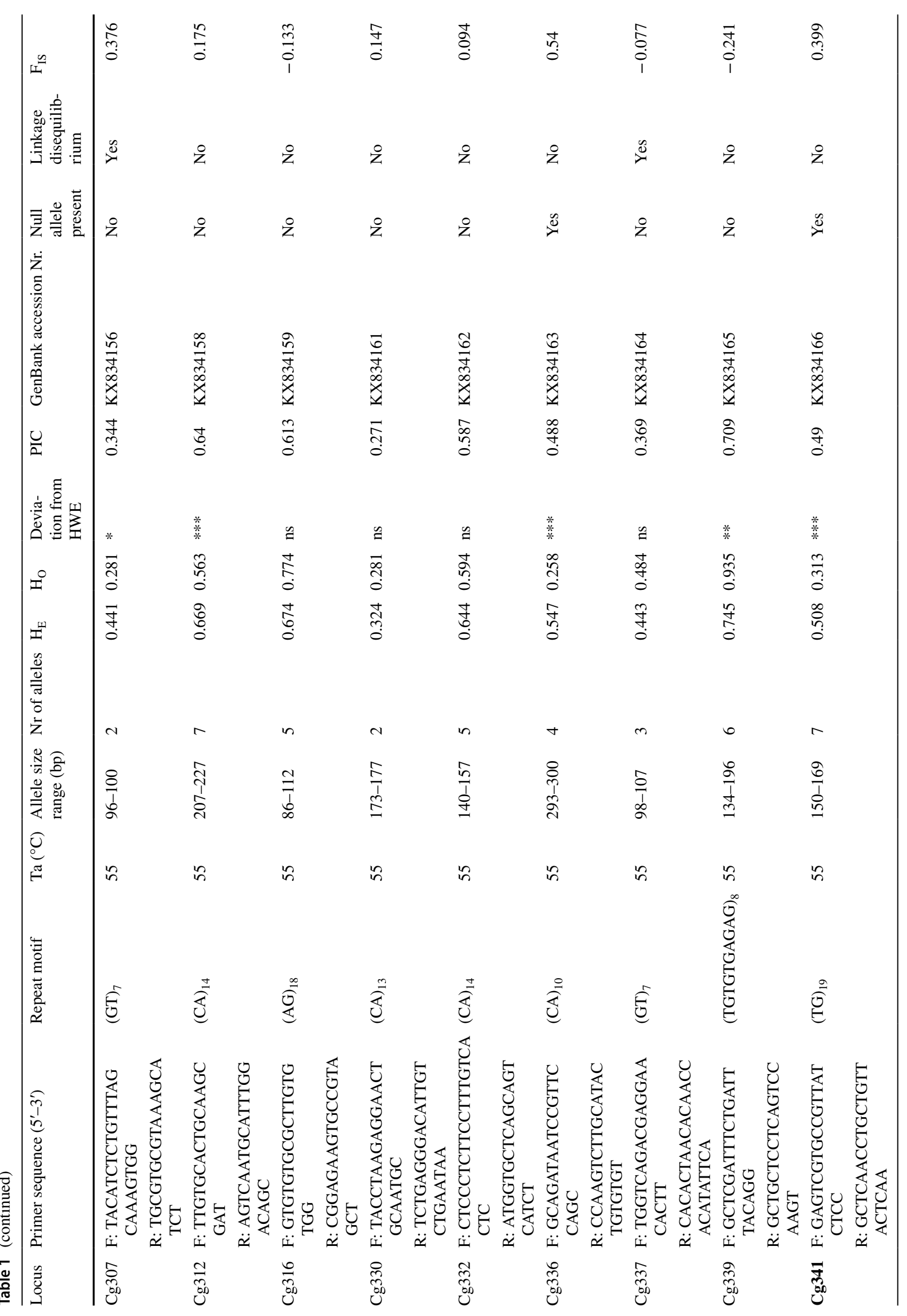




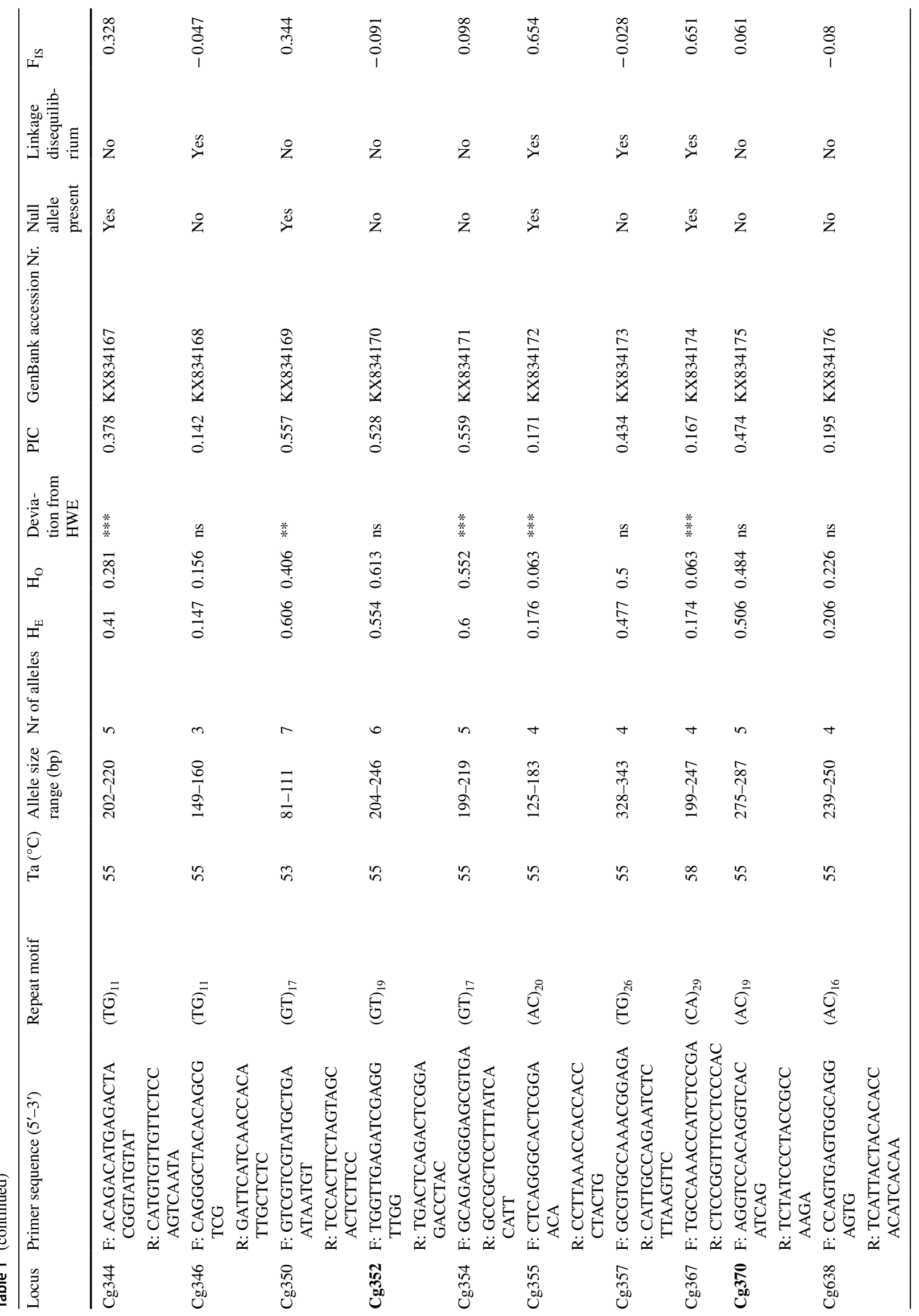




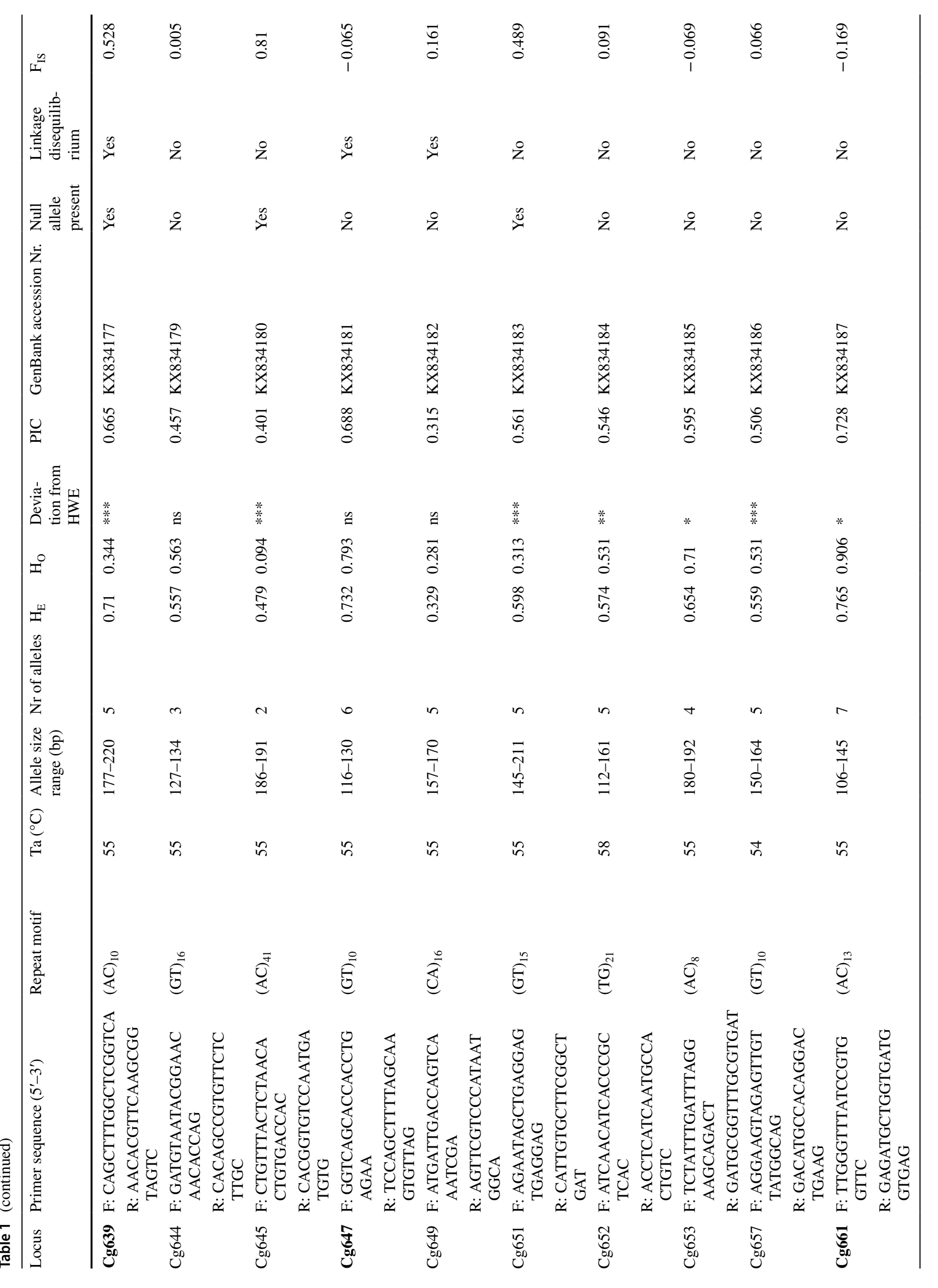




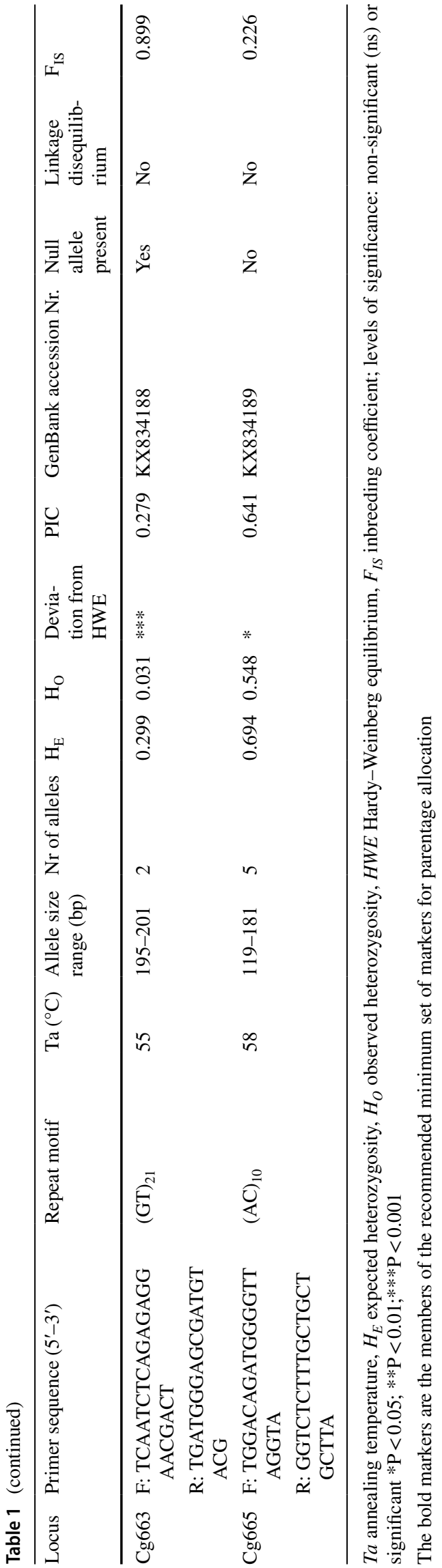

The expected heterozygosity $\left(\mathrm{H}_{\mathrm{E}}\right)$ among loci ranged from $0.147(\mathrm{Cg} 346)$ to $0.793(\mathrm{Cg} 175)$ with a mean of 0.544 (SE: 0.024), whereas the observed heterozygosity $\left(\mathrm{H}_{\mathrm{O}}\right)$ ranged from $0.031(\mathrm{Cg} 663)$ to $1.000(\mathrm{Cg} 003)$ with a mean of 0.519 (SE: 0.037). Thirty-one loci showed significant deviation from HWE. The deviation is partly due to the heterozygous deficiency at 24 loci, on the other hand, is due to heterozygosity excess at seven loci. [2], probably due to the interference of the different management practices adopted for the population studied. Selection, artificial mating system, fluctuations in population size or stocking may also explain deviations from HWE [19-21]. Probability of nullalleles was detected in the case of 12 markers (Table 1).

No parental relationships were identified by the exclusion or the maximum likelihood methods. However, the maximum likelihood analyses of relatedness showed a high probability of full-sib or half-sib relationships between individuals. All the individuals showed relationships with at least two specimens, while three of them had ten probable relatives (data not shown). In addition, linkage disequilibrium was assumed in the case of 16 markers. Nevertheless, the high number of related individuals can lead to spurious associations in the estimation of random distribution. The overall $\mathrm{F}_{\mathrm{IS}}$ values were 0.063 , while 29 markers had positive and 20 negative $\mathrm{F}_{\mathrm{IS}}$ values (Table 1). The calculation of the minimum set of markers for parentage allocation or for identification over $99 \%$ probability resulted in a marker set containing 14 markers (Table 1).

\section{Discussion}

In the present study, 49 new Clarias gariepinus microsatellites were characterized. The applied method for isolation of microsatellite repeat containing sequences was highly efficient (more than $90 \%$ of the sequences contained repeats). It is a cost-effective and time-saving method when we need efficient, highly polymorphic markers in enough number for population genetic analysis and not for genome-wide screening. The "universal", tailed primer based fluorescent labelling of amplicons [11] was also used successfully; therefore we could further reduce the cost of the analysis..

However the mean number of alleles was moderate $(5.06 \pm 1.9)$, compared to the average of freshwater fish $(9.1 \pm 6.1)$ and the bred and natural African catfish populations (ranging from $3.80 \pm 0.84$ to $10.83 \pm 3.66$ ) in Kenya [2, 22], 28 of the isolated markers had moderately high or high PIC values $(>0.5)$. These markers are recommended for population genetic analyses [23] even in closely related species.

The genetic effects of long-term intensive breeding were also investigated on the examined Hungarian African catfish population. The result of "closed" breeding (without 
or rare population refreshing) is frequently the degradation of genetic variability and inbreeding. These effects weer described in some Thai [5] and South Indian [24] populations of catfish. While the variability in "open" breeding system at African farms (they have collected males from wild habitats regularly to provide milt for egg fertilization) is higher than in the natural lakes [2]. Among the Hungarian population, the expected and observed heterozygosity differed significantly from each other in case of most markers. The heterozygote surplus and deficiency varied from marker to marker; the differences compensated each other in overall analyses. The inbreeding coefficient also showed the presence of heterozygote surplus and deficiency in a wide range (from -0709 to 0899) at different markers. Similar effects were observed in the Indian bred populations of African catfish [24] All these can be the consequence of intra-population genetic structures (non random mating), or small founder group with rare and unsystematic crossbreeding with other strains. This phenomenon of structured populations was also observed in the bred populations of Thailand [5]. In addition, the high number of probable nullalleles and linkage disequilibrium (Table 1) can also be the consequence of intra-population genetic structures or the small numbers of analysed individuals and not the real physical linkage on a chromosome.

The presence of intra-population genetic structures was confirmed by the maximum likelihood estimation of relatedness and the parentage allocation. Although, none of these two methods identified parental relationships among the individuals. The maximum likelihood analyses highlighted the presence of a high number of half-sib and full-sib individuals in the analysed group. During the parentage analyses, the most efficient set of markers was also calculated. The marker set contains 14 markers (Table 1) and usable for parentage allocation or for identification of individuals over 99\% probability in exclusion analyses.

In conclusion, 49 newly isolated $C$. gariepinus microsatellites were tested and characterised. Those can be an important genetic toolkit for the genetic diversity and population structure analysis of African catfish populations.

Based on a Hungarian population, an effective set of markers were identified for parentage analyses. In this population, the genetic variation is recommended to be increased and the relatedness should be decreased. The introduction of breeders from other "domesticated" and/or genetically improved populations are the most obvious solution. Furthermore, the breed stock size should be maximized and at least 50 breeding pairs are recommended to use from generation to generation in order to avoid inbreeding.

Acknowledgements Open access funding provided by Szent István University (SZIE). This study was supported by OTKA (Hungarian Scientific Research Fund) K105393 project and the Higher Education
Institutional Excellence Program FEKUT2019: TUDFO/47138/2019ITM awarded by the Ministry of Human Capacities (Hungary).

\section{Compliance with ethical standards}

Conflict of interest The authors declare that they have no conflict of interest.

Open Access This article is distributed under the terms of the Creative Commons Attribution 4.0 International License (http://creativeco mmons.org/licenses/by/4.0/), which permits unrestricted use, distribution, and reproduction in any medium, provided you give appropriate credit to the original author(s) and the source, provide a link to the Creative Commons license, and indicate if changes were made.

\section{References}

1. FAO (2018) Fishery and Aquaculture Statistics Statistiques des pêches et de l' aquaculture Estadísticas de pesca y acuicultura. Fao. https://doi.org/10.5860/CHOICE.50-5350

2. Barasa J, Mdyogolo S, Abila R, Grobler PJ, Skilton R, Bindeman H, Njahira NM, Chemoiwa E, Dangasuk OG, Kaunda-Arara B, Verheyen E (2017) Genetic diversity and population structure of the African catfish, Clarias gariepinus (Burchell, 1822) in Kenya: implication for conservation and aquaculture. Belg J Zool. https ://doi.org/10.26496/bjz.2017.9

3. Holmlund CM, Hammer M (2004) Effects of fish stocking on ecosystem services: an overview and case study using the Stockholm archipelago. Environ Manage. https://doi.org/10.1007/s0026 7-004-0051-8

4. Chauhan T, Rajiv K (2010) Molecular markers and their applications in fisheries and aquaculture. Adv Biosci Biotechnol. https:// doi.org/10.4236/abb.2010.14037

5. Wachirachaikarn A, Rungsin W, Srisapoome P, Na-Nakorn U (2009) Crossing of African catfish, Clarias gariepinus (Burchell, 1822) strains based on strain selection using genetic diversity data. Aquaculture. https://doi.org/10.1016/j.aquaculture.2009.01.036

6. Galbusera P, Volckaert FA, Hellemans B, Ollevier F (1996) Isolation and characterization of microsatellite markers in the African catfish Clarias gariepinus (Burchell, 1822). Mol Ecol. https://doi. org/10.1111/j.1365-294X.1996.tb00366.X

7. Yue GH, Kovacs B, Orban L (2003) Microsatellites from Clarias batrachus and their polymorphism in seven additional catfish species. Mol Ecol Notes. https://doi.org/10.104 6/j.1471-8286.2003.00486

8. Yue GH, Kovacs B, Orban L (2010) A new problem with crossspecies amplification of microsatellites: generation of non-homologous products. Zool Res 31:131-140

9. Glenn TC, Schable NA (2005) Isolating microsatellite DNA loci. Methods Enzymol. https://doi.org/10.1016/S0076-6879(05)95013 $-1$

10. Untergasser A, Nijveen H, Rao X et al (2007) Primer3Plus, an enhanced web interface to Primer3. Nucleic Acids Res. https:// doi.org/10.1093/nar/gkm306

11. Shimizu M, Kosaka N, Shimada T et al (2002) Universal fluorescent labeling (UFL) method for automated microsatellite analysis. DNA Res. https://doi.org/10.1093/dnares/9.5.173

12. Park SDE (2001) Trypanotolerance in West African cattle and the population genetics effects of selection. Ph.D. thesis, University of Dublin 
13. Peakall R, Smouse PE (2012) GenALEx 6.5: genetic analysis in Excel. Population genetic software for teaching and research-an update. Bioinformatics. https://doi.org/10.1093/bioinformatics/ bts460

14. Belkhir K, Borsa P, Chikhi L, Raufaste N, Bonhomme F (2004) 1996-2004 GENETIX 4.05, logiciel sous Windows TM pour la génétique des populations. Laboratoire Génome, Populations, Interactions, CNRS UMR 5171, Université de Montpellier II, Montpellier (France)

15. Sekino M, Kakehi S (2012) PARFEX v1.0: an EXCEL TM based software package for parentage allocation. Conserv Genet Res 4(275):278. https://doi.org/10.1007/s12686-011-9523-3

16. Kalinowski ST, Wagner AP, Taper ML (2006) ML-Relate: a computer program for maximum likelihood estimation of relatedness and relationship. Mol Ecol Not. https://doi.org/10.111 1/j.1471-8286.2006.01256.x

17. Van Oosterhout C, Hutchinson WF, Wills DPM, Shipley P (2004) MICRO-CHECKER: software for identifying and correcting genotyping errors in microsatellite data. Mol Ecol Not. https://doi.org /10.1111/j.1471-8286.2004.00684.x

18. Goudet J (2001) FSTAT, a program to estimate and test gene diversities and fixation indices, ver. 2.9.3. AN UPDATE FOR Goudet J (1995). FSTAT (vers. 1.2): a computer program to calculate F-statistics. J Hered. 86:485-186. https://en.bio-soft.net/ tree/FSTAT.html

19. Smouse PE, Whitehead MR, Peakall R (2015) An informational diversity framework, illustrated with sexually deceptive orchids in early stages of speciation. Mol Ecol Resour. https://doi. org/10.1111/1755-0998.12422

20. Allendorf F, Luikart G, Aitken S (2013) Conservation and the genetics of populations. Livro. https://doi.org/10.1093/jhered/ es1039

21. Endo T, Sekino M, Fujiwara A, Sogabe A (2018) Development and characterization of 19 novel microsatellite markers in the Pacific seaweed pipefish Syngnathus schlegeli using next-generation sequencing. Mol Biol Rep. https://doi.org/10.1007/s1103 3-018-4396-0

22. De Woody JA, Avise JC (2000) Microsatellite variation in marine, freshwater and anadromous fishes compared with other animals. J Fish Biol. https://doi.org/10.1111/j.1095-8649.2000.tb00748.x

23. Botstein D, White RL, Skolnick M, Davis RW (1980) Construction of a genetic linkage map in man using restriction fragment length polymorphisms. Am J Hum Genet 32:314-331

24. Ezilrani P, Marimuthu K, Godwin C (2016) Genetic diversity of African catfish clarias gariepinus in south India evaluated by microsatellite DNA. Int J Zool Appl Biosci. https://doi. org/10.5281/zenodo. 1310770

Publisher's Note Springer Nature remains neutral with regard to jurisdictional claims in published maps and institutional affiliations. 